\title{
Analysis and Design of Launch Vehicle Flight Control Systems
}

\author{
Bong Wie* and Wei Du ${ }^{\dagger}$ \\ Iowa State University, Ames, IA 50011-2271 \\ and \\ Mark Whorton ${ }^{\ddagger}$ \\ NASA Marshall Space Flight Center, Huntsville, AL 35812
}

\begin{abstract}
This paper describes the fundamental principles of launch vehicle flight control analysis and design. In particular, the classical concept of "drift-minimum" and "load-minimum" control principles is re-examined and its performance and stability robustness with respect to modeling uncertainties and a gimbal angle constraint is discussed. It is shown that an additional feedback of angle-of-attack or lateral acceleration can significantly improve the overall performance and robustness, especially in the presence of unexpected large wind disturbance. Non-minimum-phase structural filtering of "unstably interacting" bending modes of large flexible launch vehicles is also shown to be effective and robust.
\end{abstract}

\section{Introduction}

Note to Session Organizer/Reviewers: This draft manuscript summarizes very preliminary results obtained during an early phase of a project for the launch vehicle flight control systems analysis and design as applied to Ares-I Crew Launch Vehicle. During the next several months, a more detailed, rigorous study will be conducted in the areas of drift-minimum vs load-minimum control, flexible-body stabilization and analysis, gain scheduling vs. adaptive control, etc. A companion paper on dynamic modeling of large flexible launch vehicles is also being submitted to this Space Exploration and Transportation GNC session.

\section{Rigid-Body Control Analysis}

Consider a simplified linear dynamical model of a launch vehicle [15], as illustrated in Fig. 2, as follows:

$$
\begin{aligned}
\ddot{\theta} & =M_{\alpha} \alpha+M_{\delta} \delta \\
\ddot{Z} & =-\frac{F}{m} \theta-\frac{N_{\alpha}}{m} \alpha+\frac{T}{m} \delta \\
\alpha & =\theta+\frac{\dot{Z}}{V}+\alpha_{w} \\
F & =T_{o}+T-D
\end{aligned}
$$

where $\theta$ is the pitch attitude, $\alpha$ the angle of attack, $Z$ the inertial Z-axis drift position of the center-of-mass, $\dot{Z}$ the inertial drift velocity, $m$ the vehicle mass, $T_{o}$ the ungimbaled sustainer thrust, $T$ the gimbaled thrust, $N=N_{\alpha} \alpha$ the aerodynamic normal (lift) force acting on the center-of-pressure, $D$ the aerodynamic axial (drag) force, $F$ the total

\footnotetext{
*Vance Coffman Endowed Chair Professor, Space Systems and Controls Laboratory, Department of Aerospace Engineering, 2271 Howe Hall, Room 2355, (515) 294-3124, bongwie@iastate.edu, Associate Fellow AIAA.

$\dagger$ Ph.D. Student, Space Systems and Controls Laboratory, Department of Aerospace Engineering, Student Member AIAA

$\ddagger$ Chief, Guidance, Navigation, and Mission Analysis Branch, mark.whorton@nasa.gov, Associate Fellow AIAA.
} 


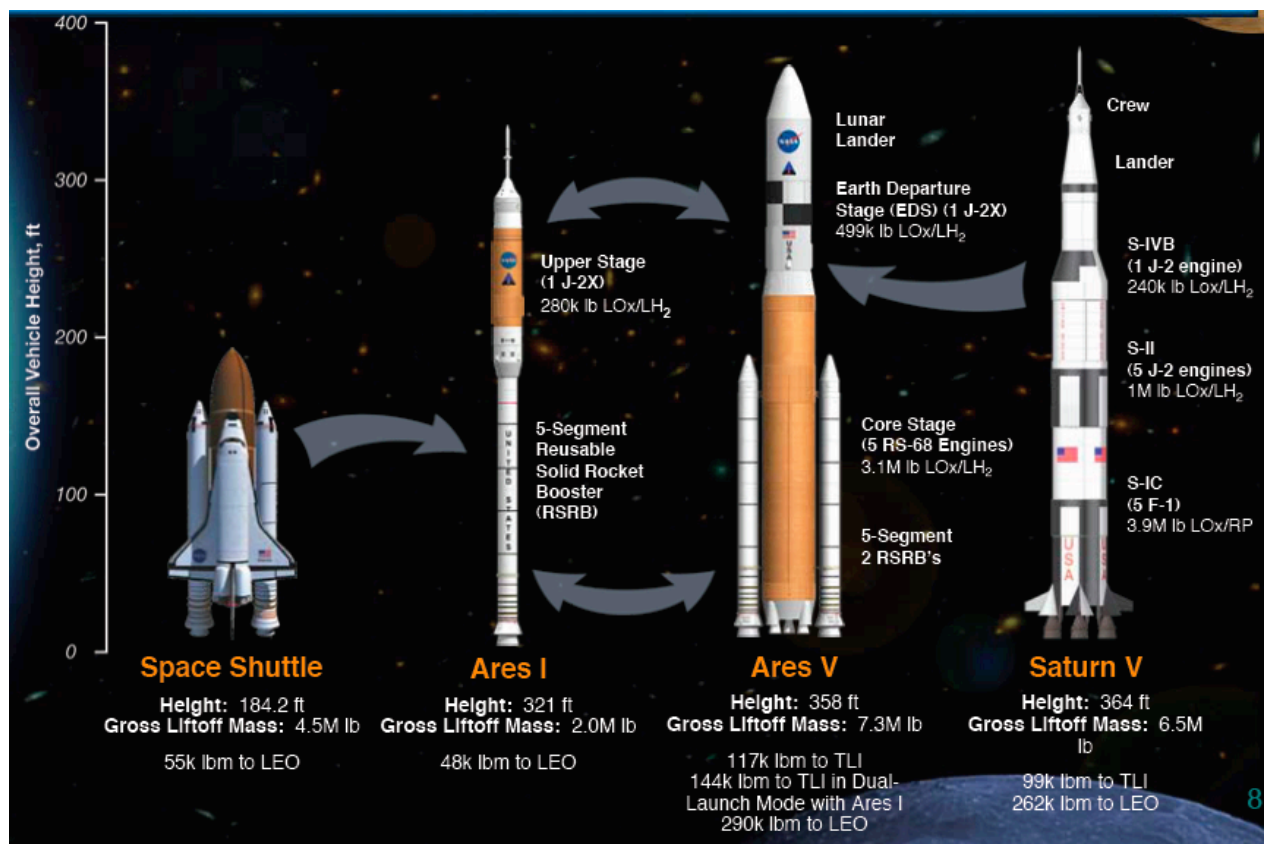

Figure 1. Comparison of Space Shuttle, Ares I, Ares V, and Saturn V Launch Vehicles [1].

x-axis force, $\delta$ the gimbal deflection angle, $V$ the vehicle velocity, $\alpha_{w}=V_{w} / V$ the wind-induced angle of attack, $V_{w}$ the wind disturbance velocity, and

$$
\begin{aligned}
M_{\alpha} & =x_{c p} N_{\alpha} / I_{y} \\
M_{\delta} & =x_{c g} T / I_{y} \\
N_{\alpha} & =\frac{1}{2} \rho V^{2} S C_{N_{\alpha}}
\end{aligned}
$$

where $I_{y}$ is the pitch moment of inertia. For an effective thrust vector control of a launch vehicle, we need

$$
M_{\delta} \delta_{\max }>M_{\alpha} \alpha_{\max }
$$

where $\delta_{\max }$ is the gimbal angle constraint and $\alpha_{\max }$ is the maximum wind-induced angle of attack.

The open-loop transfer functions from the control input $\delta(s)$ can then be obtained as

$$
\begin{aligned}
& \frac{\theta(s)}{\delta(s)}=\frac{s}{\Delta(s)}\left[M_{\delta}\left(s+\frac{N_{\alpha}}{m V}\right)+\frac{M_{\alpha} T}{m V}\right] \\
& \frac{Z(s)}{\delta(s)}=\frac{1}{\Delta(s)}\left[\frac{T}{m}\left(s^{2}-M_{\alpha}\right)-\frac{M_{\alpha}\left(F+N_{\alpha}\right)}{m}\right] \\
& \frac{\alpha(s)}{\delta(s)}=\frac{s}{\Delta(s)}\left[\frac{T}{m V} s^{2}-M_{\delta} s+\frac{M_{\delta} F}{m V}\right]
\end{aligned}
$$

where

$$
\Delta(s)=s\left[s^{3}+\frac{N_{\alpha}}{m V} s^{2}-M_{\alpha} s+\frac{M_{\alpha} F}{m V}\right]
$$

Consequently, the 4 th-order system described by Eq. (1) - (3) is completely controllable by $\delta$ and is observable by $Z$; however, the system is not observable by $\theta$ and $\alpha$.

In 1959, Hoelkner introduced the "drift-minimum" and "load-minimum" control concepts as applied to the launch vehicle flight control system [6]. The concepts have been further investigated in [7-14]. Basically, Hoelkner's controller utilizes a full-state feedback control of the form

$$
\delta=-K_{1} \theta-K_{2} \dot{\theta}-K_{3} \alpha
$$




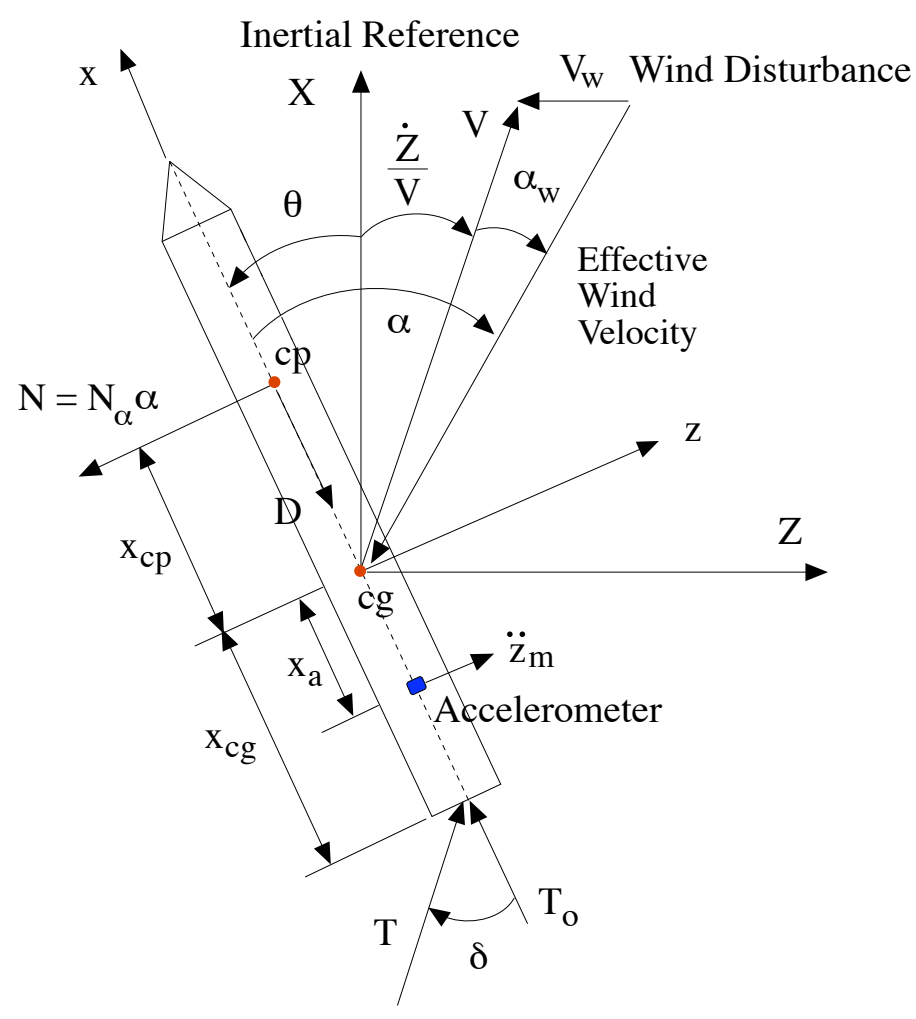

Figure 2. Simplified pitch-axis model of a launch vehicle.

for a 3rd-order dynamical model of the form

$$
\frac{d}{d t}\left[\begin{array}{c}
\theta \\
\dot{\theta} \\
\alpha
\end{array}\right]=\left[\begin{array}{ccc}
0 & 1 & 0 \\
0 & 0 & M_{\alpha} \\
-F /(m V) & 1 & -N_{\alpha} /(m V)
\end{array}\right]\left[\begin{array}{c}
\theta \\
\dot{\theta} \\
\alpha
\end{array}\right]+\left[\begin{array}{c}
0 \\
M_{\delta} \\
T /(m V)
\end{array}\right] \delta+\left[\begin{array}{c}
0 \\
0 \\
\dot{\alpha}_{w}
\end{array}\right]
$$

This 3rd-order system is observable by $\theta$ or $\alpha$. The feedback gains are to be properly selected to minimize the lateral drift velocity $\dot{Z}=V\left(\alpha-\theta-\alpha_{w}\right)$ or the bending moment caused by the angle of attack. Note that

$$
\frac{\dot{Z}}{V} \equiv \gamma=\alpha-\theta-\alpha_{w}
$$

where $\gamma$ is often called the flight-path angle.

Instead of measuring the angle-of-attack, we may employ a body-mounted accelerometer, as illustrated in Fig. 2, as follows:

$$
\begin{aligned}
\delta & =-K_{1} \theta-K_{2} \dot{\theta}+K_{a} \ddot{z}_{m} \\
& =-K_{1} \theta-K_{2} \dot{\theta}+K_{a}\left(-\frac{N_{\alpha}}{m} \alpha+\frac{T}{m} \delta+\frac{x_{a}}{m} \ddot{\theta}\right) \\
& =-K_{1} \theta-K_{2} \dot{\theta}+K_{a} \frac{x_{a}}{m} \ddot{\theta}-K_{a} \frac{N_{\alpha}}{m} \alpha+K_{a} \frac{T}{m} \delta
\end{aligned}
$$

Because the resulting effect of $\ddot{z}_{m}$ feedback is basically the same as the $\alpha$ feedback, we consider here only the control logic described by Eq. (13).

Substituting Eq. (13) into Eq. (1) - (2) or Eq. (14), we obtain the closed-loop transfer function from the wind disturbance $\alpha_{w}(s)$ to the drift velocity $\dot{Z}(s)$ as

$$
\frac{\dot{Z}}{\alpha_{w} V}=-\frac{A_{2} s^{2}+A_{1} s+A_{o}}{s^{3}+B_{2} s^{2}+B_{1} s+B_{o}}
$$


where

$$
\begin{aligned}
& B_{2}=M_{\delta} K_{2}+\frac{T}{m V}\left(K_{3}+\frac{N_{\alpha}}{T}\right) \\
& B_{1}=M_{\delta}\left(K_{1}+K_{3}\right)-M_{\alpha}+\frac{K_{2} T}{m V}\left(M_{\alpha}+\frac{M_{\delta} N_{\alpha}}{T}\right) \\
& B_{o}=\frac{T K_{1}}{m V}\left(M_{\alpha}+\frac{M_{\delta} N_{\alpha}}{T}\right)-\frac{F}{m V}\left(M_{\delta} K_{3}-M_{\alpha}\right) \\
& A_{2}=\frac{T}{m V}\left(K_{3}+\frac{N_{\alpha}}{T}\right) \\
& A_{1}=\frac{K_{2} T}{m V}\left(M_{\alpha}+\frac{M_{\delta} N_{\alpha}}{T}\right) \\
& A_{o}=B_{o}
\end{aligned}
$$

For a unit-step wind disturbance of $\alpha_{w}(s)=1 / s$, the steady-state value of $\dot{Z}$ can be found as

$$
\frac{\dot{Z}_{s s}}{V}=\lim _{s \rightarrow 0} \frac{-\left(A_{2} s^{2}+A_{1} s+A_{o}\right)}{s^{3}+B_{2} s^{2}+B_{1} s+B_{o}}=\frac{-A_{o}}{B_{o}}=-1
$$

The launch vehicle drifts along the wind direction with $\dot{Z}_{s s}=-V_{w}$ and also with $\theta=\dot{\theta}=\alpha=\delta=0$ as $t \rightarrow \infty$. It is interesting to notice that the steady-state drift velocity (or the flight path angle) is independent of feedback gains provided an asymptotically stable closed-loop system with $B_{o} \neq 0$.

If we choose the control gains such that $B_{o}=0$ (i.e., one of the closed-loop system roots is placed at $s=0$ ), the steady-state value of $\dot{Z}$ becomes

$$
\frac{\dot{Z}_{s s}}{V}=\lim _{s \rightarrow 0} \frac{-\left(A_{2} s+A_{1}\right)}{s^{2}+B_{2} s+B_{1}}=\frac{-A_{1}}{B_{1}}=\frac{-1}{1+C}
$$

where

$$
C=\frac{m V\left[M_{\delta}\left(K_{1}+K_{3}\right)-M_{\alpha}\right]}{M_{\alpha} K_{2} T+M_{\delta} N_{\alpha} / T}
$$

For a stable closed-loop system with $M_{\delta}\left(K_{1}+K_{3}\right)-M_{\alpha}>0$, we have $C>1$ and

$$
\left|\dot{Z}_{s s}\right|<V_{w}
$$

when $B_{o}=0$. The drift-minimum condition, $B_{o}=0$, can be rewritten as

$$
\frac{M_{\delta} K_{3}-M_{\alpha}}{M_{\delta} K_{1}}=\frac{N_{\alpha}}{F}\left(1+\frac{x_{c p}}{x_{c g}}\right)
$$

Consider the following closed-loop transfer functions:

$$
\begin{gathered}
\frac{\alpha}{\alpha_{w}}=-\frac{s\left(s^{2}+M_{\delta} K_{2} s+M_{\delta} K_{1}\right)}{s^{3}+B_{2} s^{2}+B_{1} s+B_{o}} \\
\frac{\delta}{\alpha_{w}}=-\frac{s\left(K_{3} s^{2}+M_{\alpha} K_{2} s+M_{\alpha} K_{1}\right)}{s^{3}+B_{2} s^{2}+B_{1} s+B_{o}}
\end{gathered}
$$

For a unit-step wind disturbance of $\alpha_{w}(s)=1 / s$, we have $\alpha=\delta=0$ as $t \rightarrow \infty$. However, for a unit-ramp wind disturbance of $\alpha_{w}(s)=1 / s^{2}$, we have

$$
\begin{aligned}
& \lim _{t \rightarrow \infty} \alpha(t)=M_{\delta} K_{1} \\
& \lim _{t \rightarrow \infty} \delta(t)=M_{\alpha} K_{1}
\end{aligned}
$$

Consequently, the bending moment induced by $\alpha$ and $\delta$ can be minimized by choosing $K_{1}=0$, which is the "loadminimum" condition introduced by Hoelkner [6]. The closed-loop system with $K_{1}=0$ is unstable because

$$
B_{o}=-\frac{F}{m V}\left(M_{\delta} K_{3}-M_{\alpha}\right)<0
$$


However, the load-minimum control for short durations has been known to be acceptable provided a deviation from the nominal flight trajectory is permissible.

A set of full-state feedback control gains, $\left(K_{1}, K_{2}, K_{3}\right)$, can be found by using a pole-placement approach or the linear-quadratic-regulator (LQR) control method [21-22], as follows:

$$
\min _{\delta} \int_{0}^{\infty}\left(x^{T} Q x+\delta^{2}\right) d t
$$

subject to $\dot{x}=A x+B \delta$ and $\delta=-K x$ where $x=\left[\begin{array}{lll}\theta & \dot{\theta} & \alpha\end{array}\right]^{T}$ and $K=\left[\begin{array}{lll}K_{1} & K_{2} & K_{3}\end{array}\right]$.

\section{Rigid-Body Control Example} in [15]

Consider a launch vehicle control design example discussed by Greensite in [15]. Its basic parameters are given as

$$
\begin{array}{lll}
I_{y}=2.43 E 6 \mathrm{slug}-\mathrm{ft}^{2}, & m=5830 \mathrm{slug}, & T=341,000 \mathrm{lb} \\
F=375,000 \mathrm{lb}, & x_{c p}=38 \mathrm{ft}, & x_{c g}=32.3 \mathrm{ft} \\
V=1320 \mathrm{ft} / \mathrm{sec}, & V_{w}=132 \mathrm{ft} / \mathrm{sec}, & \alpha_{w}=5.73 \mathrm{deg} \\
N_{\alpha}=240,000 \mathrm{lb} / \mathrm{rad}, & M_{\alpha}=3.75 \mathrm{~s}^{-2}, & M_{\delta}=4.54 \mathrm{~s}^{-2}
\end{array}
$$

The open-loop poles of this example vehicle are: $-1.9767,0.0488,1.8967$

Note that the wind-induced angle of attack of 5.73 deg considered for this example in [15] is somewhat unrealistic because it will require a maximum gimbal deflection angle of

$$
\delta_{\max }>\frac{M_{\alpha}}{M_{\delta}} \alpha_{w}=4.73 \mathrm{deg}
$$

Most practical thrust vector control systems have a maximum gimbal angle constraint of about \pm 5 deg. In this paper, we also assume a second-order gimbal actuator dynamics of the form

$$
\delta(s)=\frac{\omega_{n}^{2}}{s^{2}+2 \zeta \omega_{n} s+\omega_{n}^{2}} \delta_{c}(s)
$$

where $\zeta=1$ and $\omega_{n}=50 \mathrm{rad} / \mathrm{s}$.

Table 1. Summary of rigid-body control analysis and design

\begin{tabular}{|c|c|c|c|}
\hline Case No. & Controller Type & Feedback Gains $\left(K_{1}, K_{2}, K_{3}\right)$ & Closed-Loop Poles \\
\hline 1 & $(\theta, \dot{\theta})$-Feedback Control [15] & $(2,0.8,0)$ & $-1.7488 \pm 1.3934 \mathrm{j},-0.1596$ \\
2 & Drift-Minimum Control [15] & $(2,0.8,3.614)$ & $-1.9087 \pm 4.2774 \mathrm{j}, 0.0$ \\
3 & Load-Minimum Control [15] & $(0,0.8,3.614)$ & $-1.9323 \pm 3.0533 \mathrm{j}, 0.0471$ \\
\hline 4 & LQR Control $(\mathrm{Q}=0)$ & $(0.6852,0.8491,0.9542)$ & $-1.9767,-1.8967,-0.0488$ \\
5 & Drift-Minimum Control & $(0.3220,0.8352,1.2765)$ & $-1.9767,-1.8967,0.0$ \\
6 & Load-Minimum Control & $(0,0.8352,1.2765)$ & $-3.1323,-0.7816,0.0405$ \\
\hline
\end{tabular}

\section{Flexible-Body Control Analysis}

More detailed control and stability analysis results for Figs. 10 and 11 will be included in the final manuscript. 


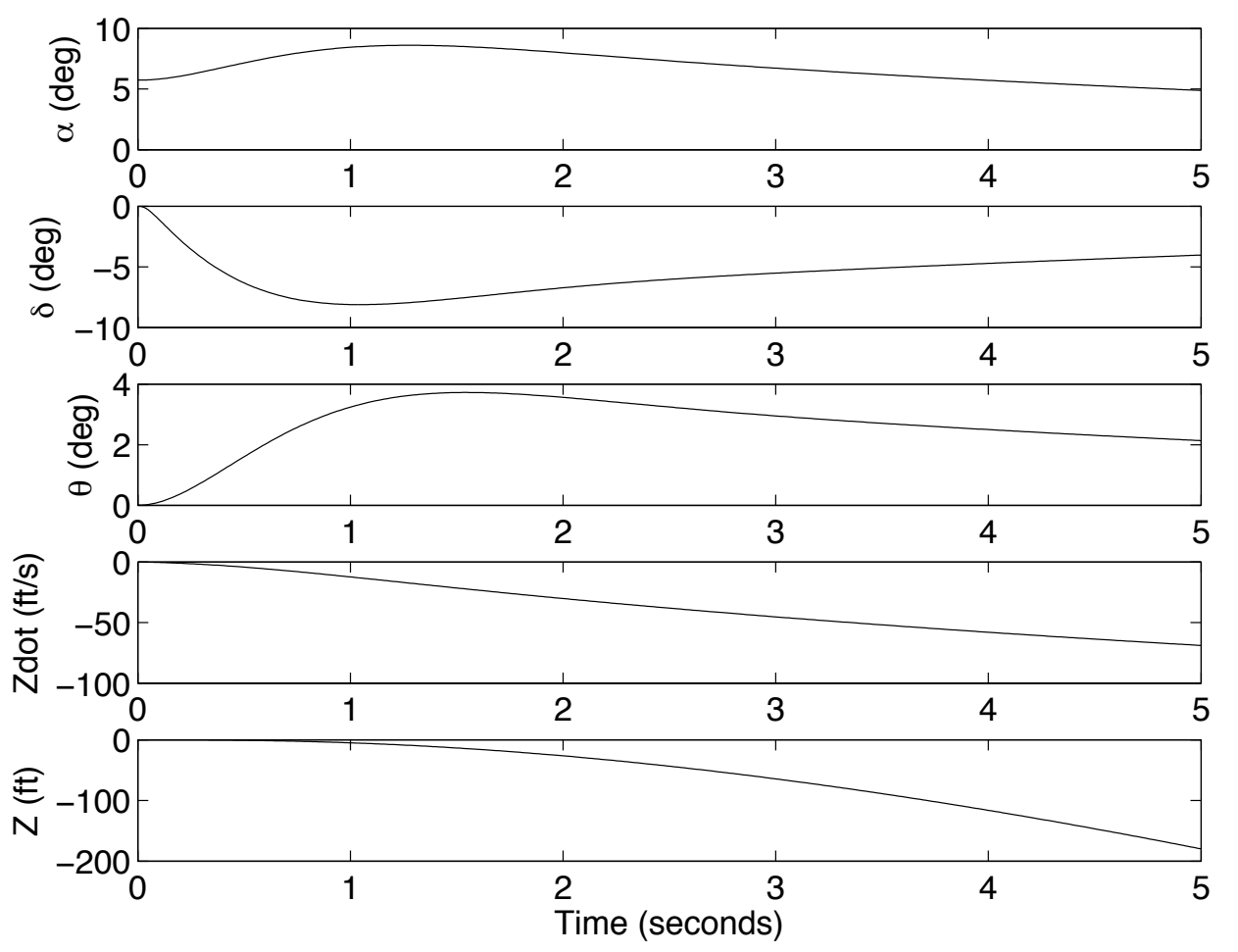

Figure 3. $(\theta, \dot{\theta})$-feedback control (Case 1).
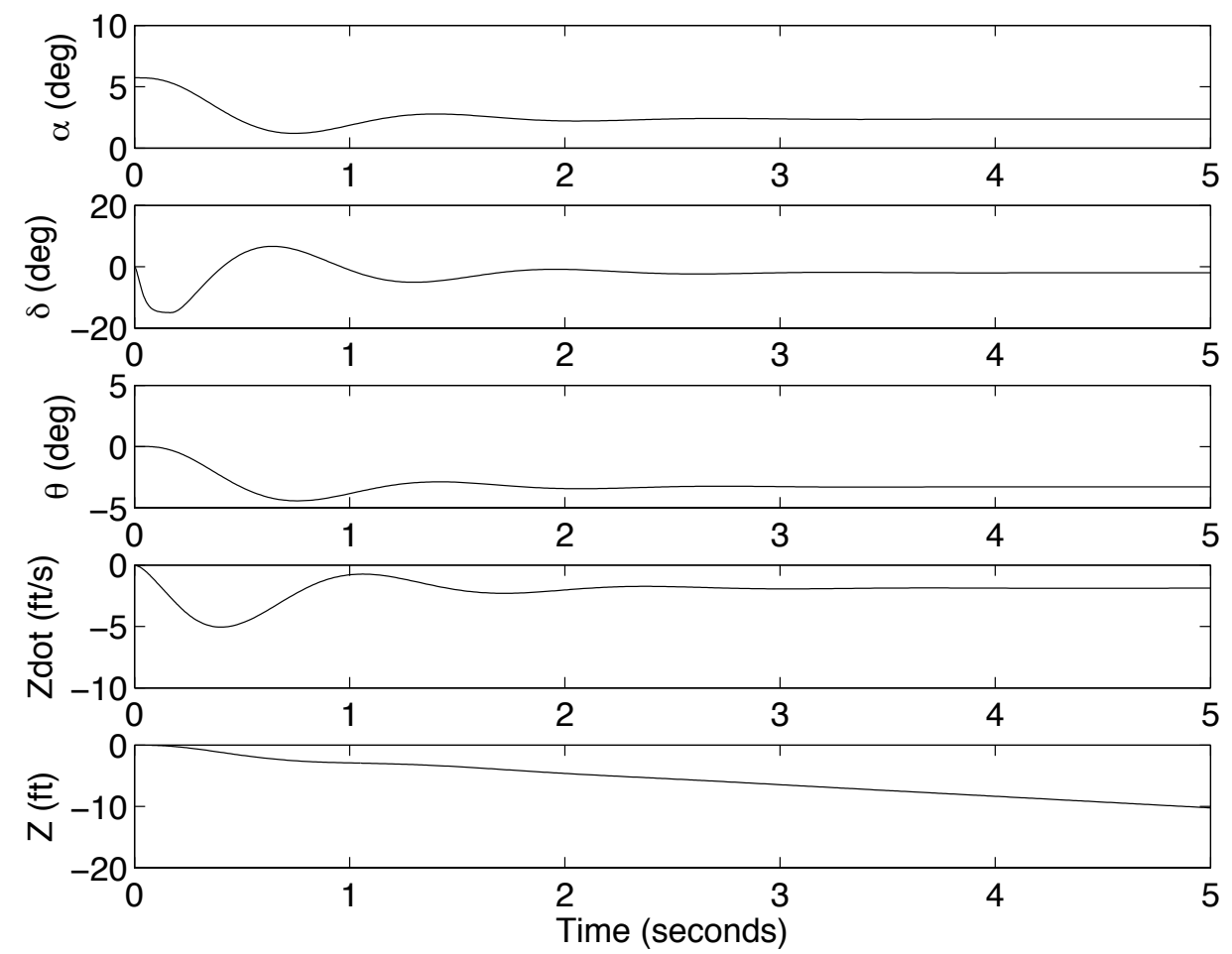

Figure 4. Drift-minimum control (Case 2). 

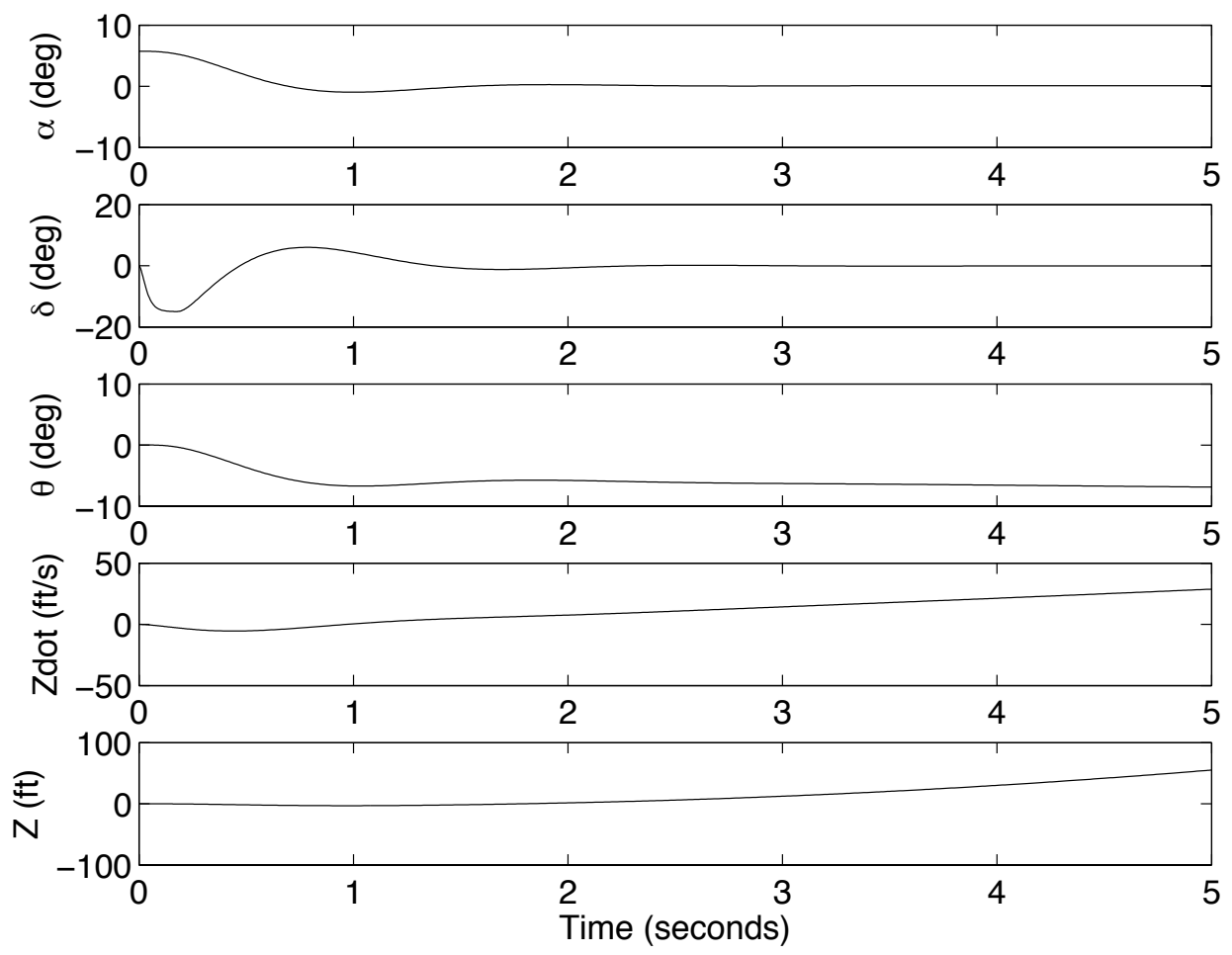

Figure 5. Load-minimum control (Case 3).
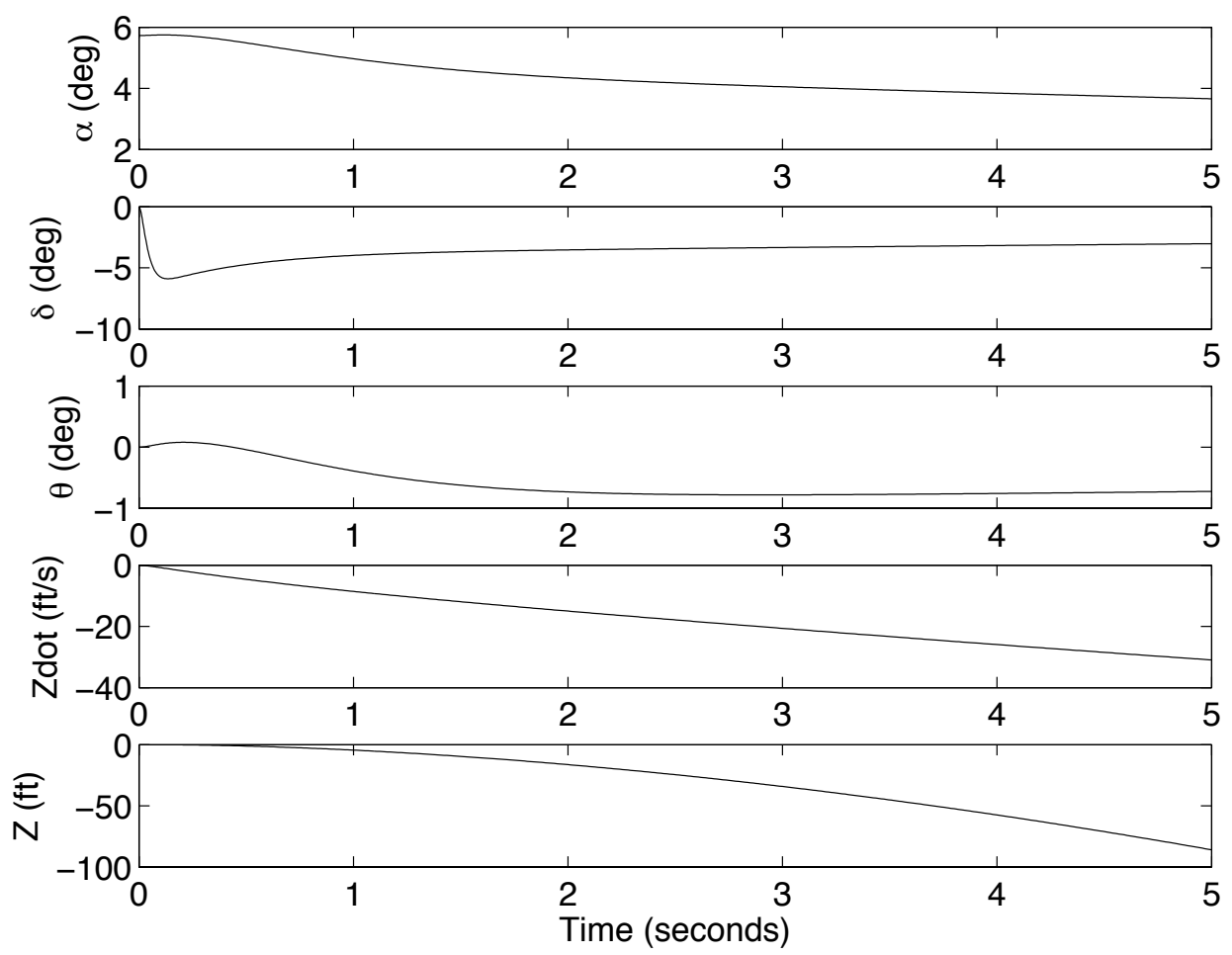

Figure 6. LQR control (Case 4). 

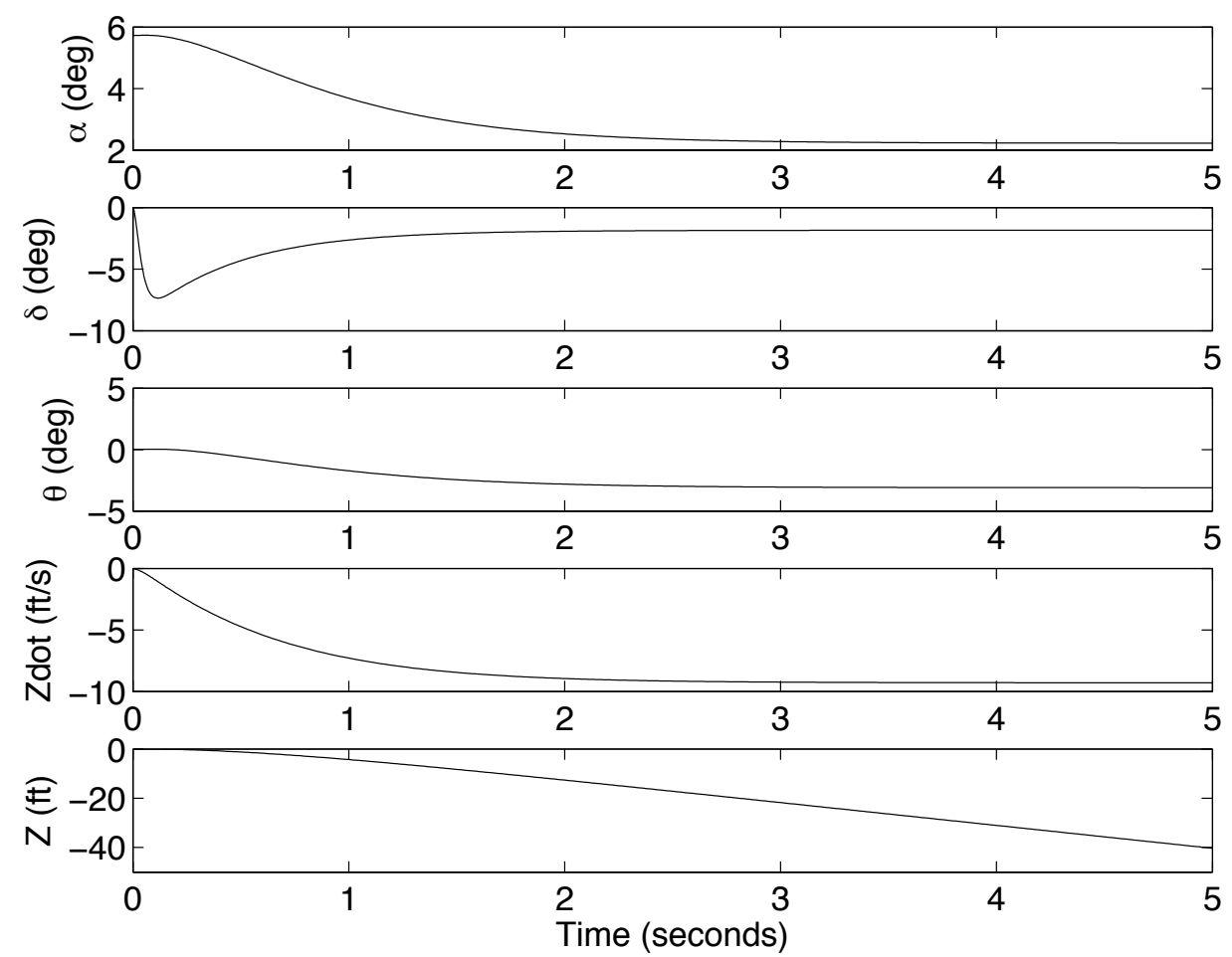

Figure 7. Drift-minimum control (Case 5).
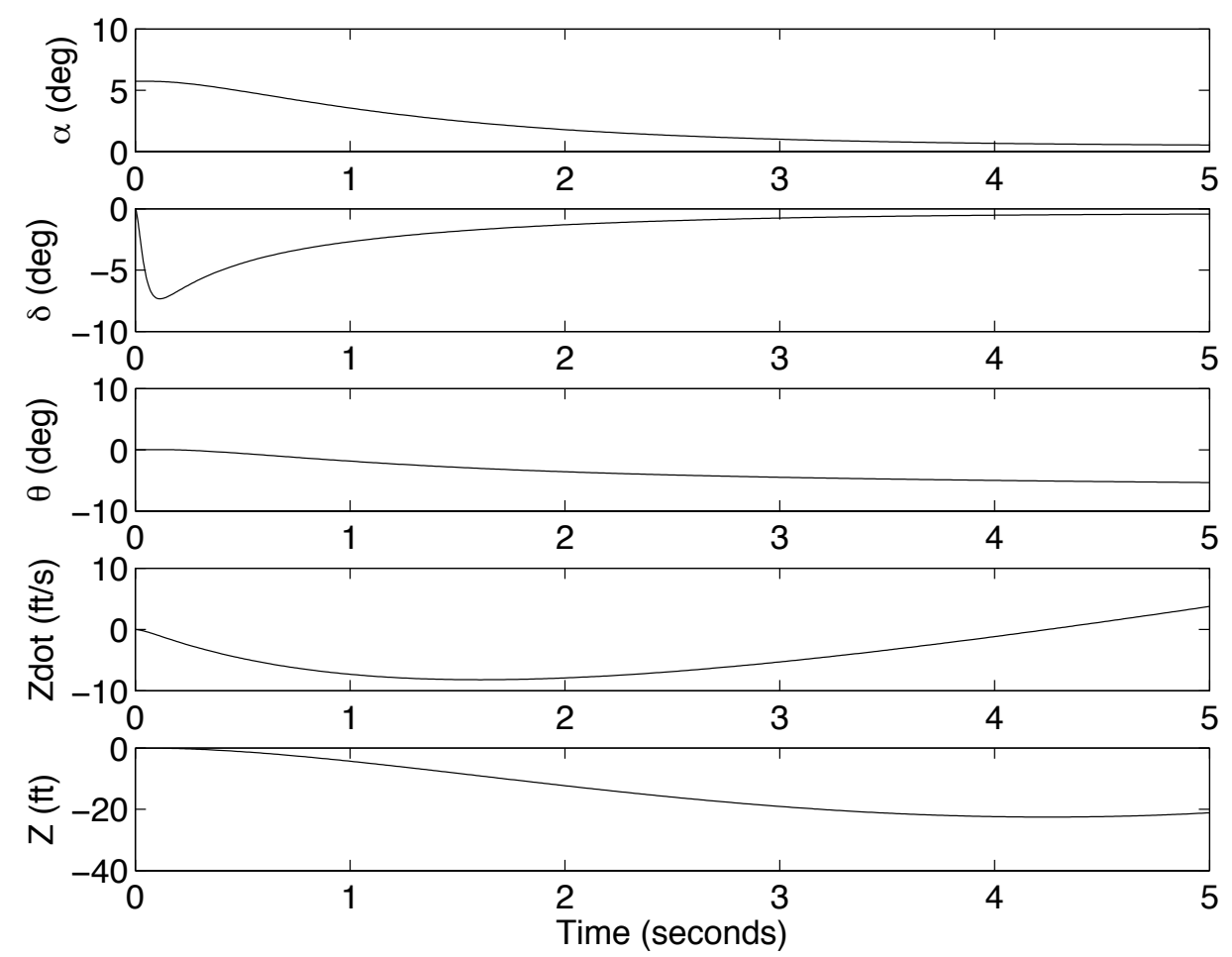

Figure 8. Load-minimum control (Case 6). 

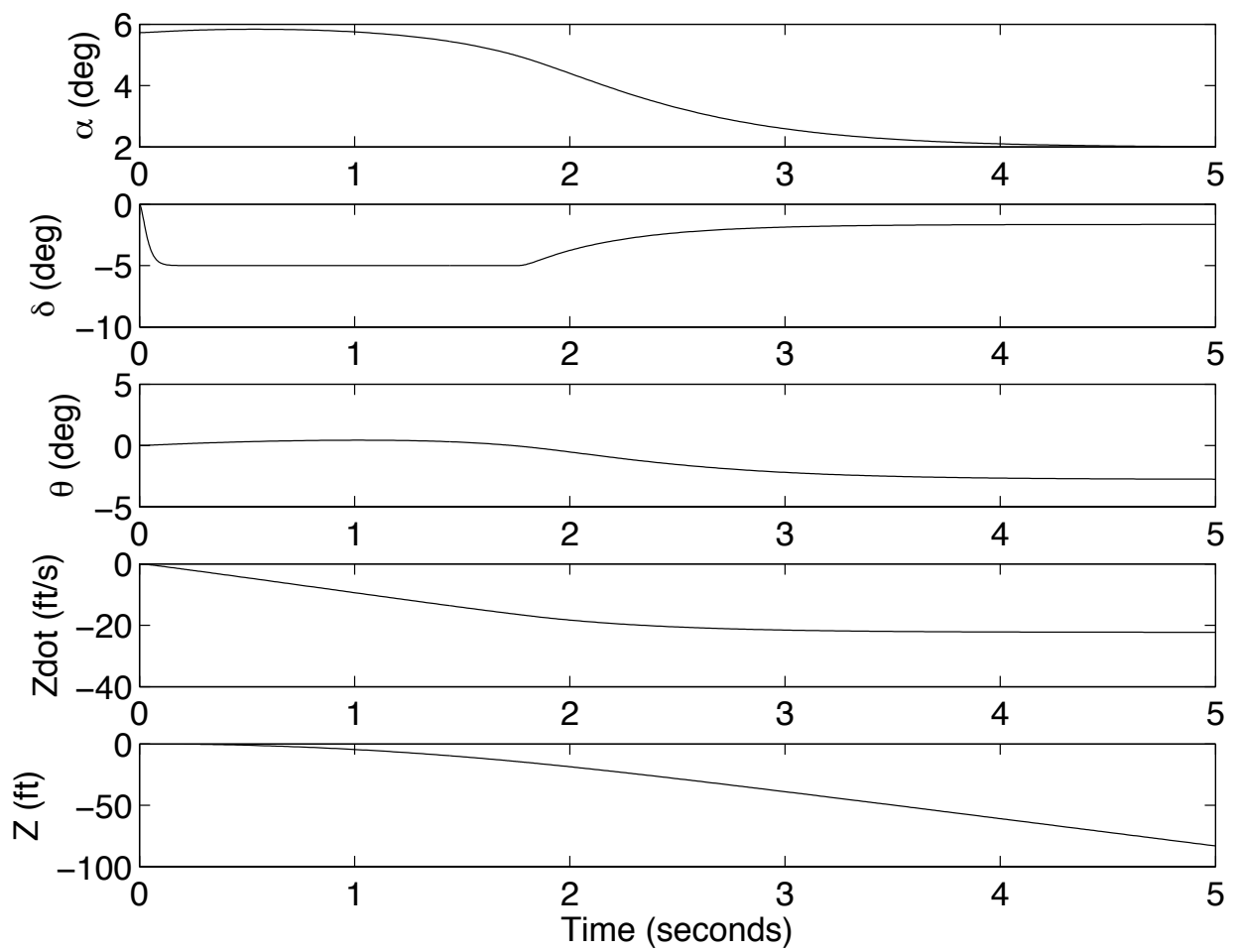

Figure 9. Case 5 (drift-minimum control) with $\delta_{\max }= \pm 5 \mathrm{deg}$.
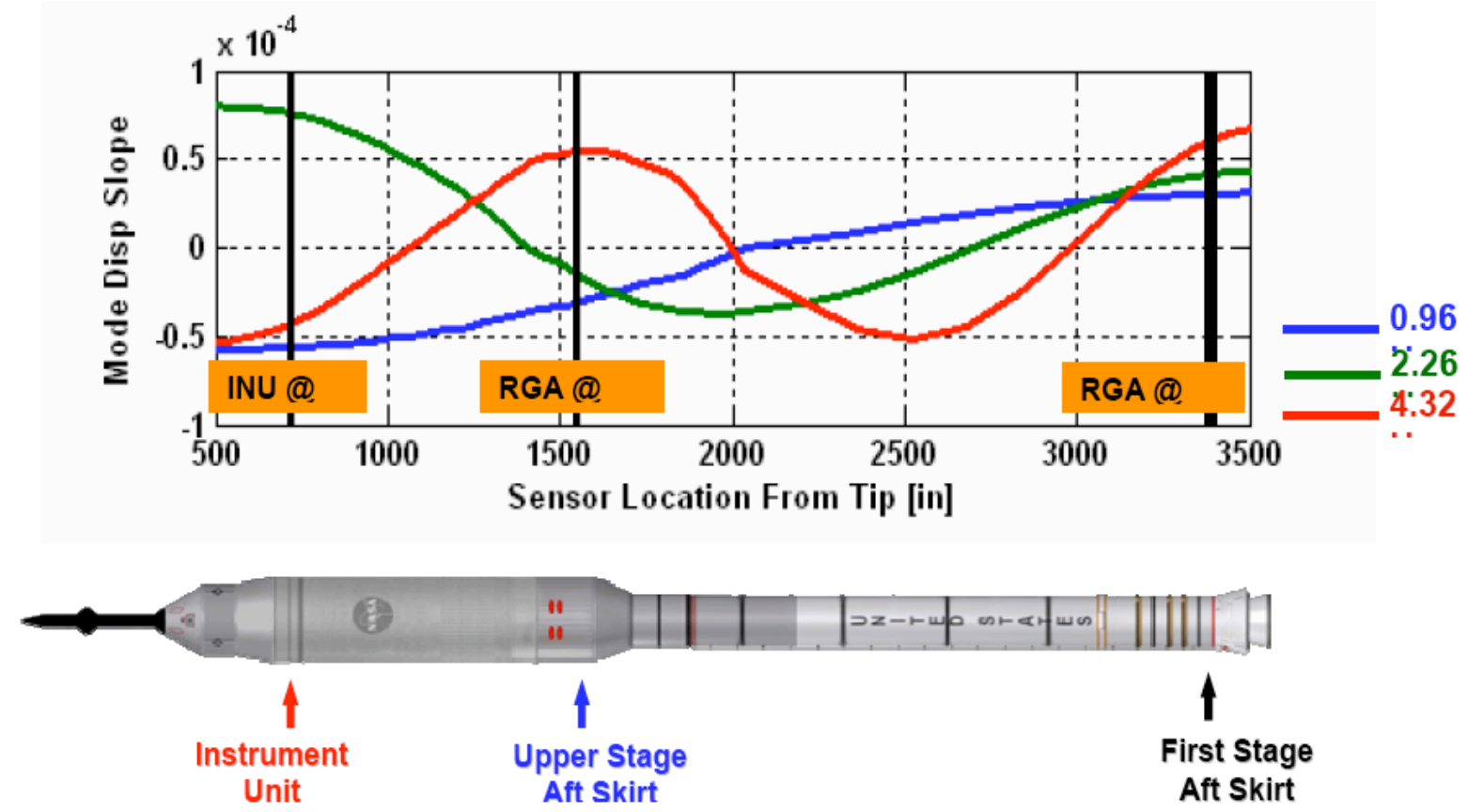

Figure 10. Illustrations of dominant bending modes and sensor locations (Ref. 2). 


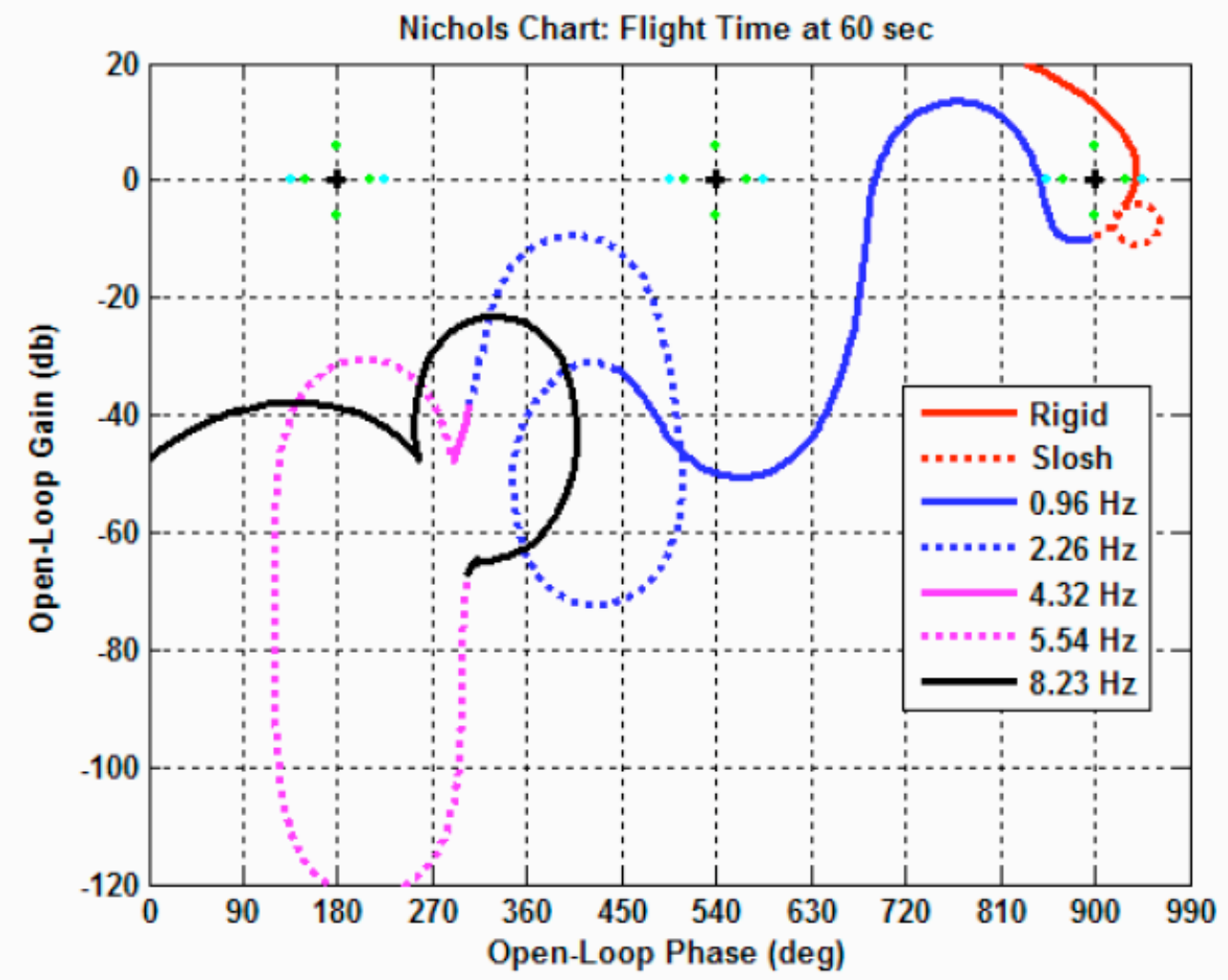

Figure 11. Nichols plot for a baseline pitch-axis flight control system (Ref. 2). 


\section{Conclusions}

\section{References}

[1] Cook, S., “Ares Project Status,” Presented at 2nd AIAA Space Exploration Conference, December 4-6, 2006.

[2] Whorton, M., Hall, C., and Cook, S., "Ascent Flight Control and Structural Interaction for the Ares-I Crew Launch Vehicle," AIAA 2007-1780, April 2007.

[3] Jang, J.-W., Bedrossian, N., Hall, R., Norris, H., Hall, C., and Jackson, M., "Initial Ares-I Bending Filter Design," AAS 07-059, February 2007.

[4] Betts, K. M., Rutherford, R. C., McDuffie, J., Johnson, M. D., Jackson, M., and Hall, C., "Time Domain Simulation of the NASA Crew Launch Vehicle," AIAA 2007-6621, August 2007.

[5] Betts, K. M., Rutherford, R. C., McDuffie, J., Johnson, M. D., Jackson, M., and Hall, C., "Stability Analysis of the NASA ARES I Crew Launch Vehicle Control System,” AIAA 2007-6776, August 2007.

[6] Hoelkner, R. F., "The Principle of of Artificial Stabilization of Aerodynamically Unstable Missiles," ABMA DA-TR-64-59, September 25, 1959.

[7] Hoelkner, R. F., "Theory of Artificial Stabilization of Missiles and Space Vehicles with Exposition of Four Control Principles,” NASA TN D-555, June 1961.

[8] Harris, R. J., "Trajectory Simulation Applicable to Stability and Control Studies of Large Multi-Engine Vehicles," NASA TN D-1838, August 1963.

[9] Harvey, C. A., "An Alternate Derivation and Interpretation of the Drift-Minimum Principle," NASA Contract NASw-563, MH MPG Report 1541-TR 15, Minneapolis-Honeywell, November 22, 1963.

[10] Garner, D., “Control Theory Handbook,” NASA TM X-53036, April 22, 1964.

[11] Rheinfurth, M. H., “The Alleviation of Aerodynamic Loads on Rigid Space Vehicles,” NASA TM X-53397, February 21, 1966.

[12] Martin, D. T., Sievers , R. F., O’Brien, R. M., and Rice, A. F., "Saturn V Guidance, Navigation, and Targeting," J. Spacecraft, Vol. 4, No. 7, 1967, pp. 891-898.

[13] Frosch, J. A. and Valley, D. P., "Saturn AS-501/S-IC Flight Control System Design,” J. Spacecraft, Vol. 4, No. 8, 1967, pp. 1003-1009.

[14] Haeussermann, W., "Description and Performance of the Saturn Launch Vehicle's Navigation, Guidance, and Control System,” NASA TN D-5869, July 1970. 1970 .

[15] Greensite, A. L., "Analysis and Design of Space Vehicle Flight Control Systems," Spartan Books, New York,

[16] Blackburn, T. R. and Vaughan, D. R., "Application of Linear Optimal Control and Filtering Theory to the Saturn V Launch Vehicle," IEEE Transactions on Automatic Control, Vol. AC-16, No. 6, Dec. 1971, pp. 799-806.

[17] Wie, B., “Thrust Vector Control Design for a Liquid Upper Stage Spacecraft," Journal of Guidance, Control, and Dynamics, Vol. 8, No. 5, 1985, pp. 566-572.

[18] Wie, B. and Byun, K. W., "New Generalized Structural Filtering Concept for Active Vibration Control Synthesis," Journal of Guidance, Control, and Dynamics, Vol. 12, No. 2, 1989, pp. 147-154.

[19] Byun, K. W, Wie, B. and Sunkel, J., "Robust Non-Minimum-Phase Compensation for a Class of Uncertain Dynamical Systems,” Journal of Guidance, Control, and Dynamics, Vol. 14, No. 6, 1991, pp. 1191-1199.

[20] Wie, B., Liu, Q. and Bauer, F., "Classical and Robust $H_{\infty}$ Control Redesign for the Hubble Space Telescope," Journal of Guidance, Control, and Dynamics, Vol. 16, No. 6, 1993, pp. 1069-1077.

[21] Bryson, A. E., Control of Spacecraft and Aircraft, Princeton University Press, 1994.

[22] Bryson, A. E., Applied Linear Optimal Control, Cambridge University Press, 2002.

[23] Wie, B., Space Vehicle Dynamics and Control, AIAA Education Series, 1998. 